\title{
Evaluation on High-Pressure Hydrogen Decompression Failure of Rubber O-ring Using Design of Experiments
}

\author{
Atsushi Koga ${ }^{1)}$ Kenichi Uchida $^{2)}$ Junichiro Yamabe ${ }^{3) .5)}$ Shin Nishimura ${ }^{4) .5)}$ \\ 1·2) NOK Corporation, 4-3-1 Tsujido-shinmachi, Fujisawa, Kanagawa, 251-0041, Japan (E-mail: koga199@nok.co.jp) \\ 3) International Research Center for Hydrogen Energy, Kyushu University, 744 Motooka, Nishi-ku, Fukuoka, 819-0395, Japan \\ 4) Department of Mechanical Engineering, Faculty of Engineering, Kyushu University, 744 Motooka, Nishi-ku, Fukuoka, \\ 819-0395, Japan
}

5) Research Center for Hydrogen Industrial Use and Storage, National Institute of Advanced Industrial Science and Technology, 744 Motooka, Nishi-ku, Fukuoka, 819-0395, Japan

Received on June, 20, 2011

Presented at EVTeC' 11 on May, 19, 2011

\begin{abstract}
The rubber O-rings used in high-pressure hydrogen environment sometimes suffer from the decrease in durability due to decompression failure. A high-pressure durability tester, which enables rubber O-rings to expose repeatedly high-pressure hydrogen gas at arbitrary test conditions, was employed, and then sensitive factors for the durability of the Orings were evaluated by using a L18 orthogonal array. Of lower-limit pressure, upper-limit pressure, material, temperature, O-ring filling ratio, holding time at lower limit, holding time at upper limit, and decompression time, it was clarified that the material, temperature, O-ring filling ratio, and decompression time were sensitive factors.
\end{abstract}

KEY WORDS: (Standardized) Materials, Elastomer, Seal, Fatigue, Reliability, (Free) Rubber, O-ring, Hydrogen, Orthogonal array [D3]

\section{INTRODUCTION}

Fuel-cell systems that use energy derived from hydrogen have received a considerable amount of attention due to the exhaustion of fossil fuels and the problems associated with global warming. To achieve widespread acceptance by society of hydrogen-based energy, it will be necessary to ensure the safety and durability of materials used for high-pressure hydrogen gas. In the case of rubber materials, there is a particular danger of internal fracture, which occurs when high-pressure hydrogen gas is suddenly decompressed. This type of fracture is usually referred to as explosive decompression failure (XDF) ${ }^{(1)}$ or blister fracture. Several reports on the blister fracture of rubber materials by highpressure carbon dioxide, nitrogen, and argon gases have been reported ${ }^{(1-5)}$. It is also reported that high-pressure hydrogen gas causes the blister fracture of rubber materials as well as other gases ${ }^{(6)}$. As for the blister fracture in high-pressure hydrogen gas, Yamabe et al. investigated the influence of filler such as carbon black and silica on the blister fracture of rubbers ${ }^{(6)}$, the method for estimating the critical hydrogen pressure at crack initiation ${ }^{(7)}$, and the relationship between the blister fracture and microstructure ${ }^{(8,9)}$ by using cylindrical specimens $(\phi 29.0 \mathrm{~mm} \times 12.5 \mathrm{~mm})$ at the hydrogen pressure of $\leq 10 \mathrm{MPa}$; however, the fracture behavior and hydrogen-permeation properties of rubber O-rings have not been fully evaluated. Moreover, although the fuel-cell systems plan to be operated at pressures from 35 to $70 \mathrm{MPa}$ and at a wide range of temperature, the durability evaluation of the rubber $\mathrm{O}$ - rings under those environmental conditions has not been conducted. The durability of rubber O-rings used as seals in highpressure hydrogen service is considered to be governed not only by the properties of the rubber materials themselves, but also by environmental conditions such as the pressure and temperature ${ }^{(1)}$. Therefore, the actual durability of O-rings needs to be comprehensively evaluated under the environmental conditions to which they are likely to be exposed during service.

The objective of this study is to clarify influencing factors on blister fracture of rubber O-rings under high-pressure hydrogen environment. In order to consider the influence of several factors on the blister fracture, eight factors, which are lower-limit pressure, upper-limit pressure, material, temperature, O-ring filling ratio, holding time at lower limit, holding time at upper limit, and decompression time, were selected. The durability test was conducted by a high-pressure hydrogen durability tester which enables the rubber O-rings to repeatedly expose highpressure hydrogen gas; then, influencing factors on the blister fracture were investigated by orthogonal experiments ${ }^{(10-13)}$.

\section{MATERIALS AND EXPERIMENTAL METHOD}

\subsection{Materials}

Ethylene-propylene-diene monomer rubber (EPDM), silicone rubber (VMQ), and hydrogenated acrylonitrile-butadiene rubber (HNBR) were employed for evaluation. By adjusting filler content, the durometer hardness of these rubber materials was set 
to be A 80 . Table 1 shows material properties of these materials. The material properties of EPDM used in our previous studies ${ }^{(14,}$ ${ }^{15)}$, whose durometer hardness was A 70, is also shown in Table 1. We refer to this material as EPDM-L. When properties of the rubber materials with a durometer hardness of A80 were compared, HNBR was the highest, while VMQ was the lowest with regard to tensile strength. As for the value of TR10, which means that shrinkage ratio is $10 \%$ at temperature-retraction (T-R) test under low temperature and is conventionally regarded as an indicator to judge rubbers at low temperature properties; VMQ was the highest, while HNBR was the lowest. The hydrogen gas permeability and diffusivity of VMQ were about 10 times higher than those of the other rubbers. This indicates VMQ is inferior to the other rubber in terms of gas barrier property. The hydrogen gas solubility of these rubbers did not show a big difference. Based on the material properties of EPDM, VMQ is a material with an excellent low temperature property and a poor gas barrier property, whereas HNBR is a high-strength material and an excellent gas barrier property. From these rubber materials, Oring specimens with a diameter of cross section of $3.5 \mathrm{~mm}$ and an inner diameter of $11.9 \mathrm{~mm}$, and sheet specimens with a thickness of $2 \mathrm{~mm}$ were molded.

\subsection{Durability tester}

Figure 1 shows a schematic representation of the highpressure hydrogen durability tester. The tester was developed in order to evaluate the durability of rubber O-ring under highpressure hydrogen gas. Hydrogen gas at $5 \mathrm{MPa}$ is compressed to $95 \mathrm{MPa}$ by compressor; then its pressured hydrogen gas is once accumulated in the pressure accumulator. After that, its high pressure hydrogen gas is repeatedly supplied to eight O-ring specimen holders installed with O-ring specimens. A manometer is equipped with the tester, and the amount of hydrogen gas penetrating the O-ring specimens $(q)$ is monitored. The hydrogen permeation is detected by the increase in hydrogen pressure of the manometer. Two types of tests can be conducted, one of which is a hydrogen permeation test, and the other of which is a pressure cycle test. This tester can be operated at hydrogen pressures ranging from 6 to $90 \mathrm{MPa}$ for the cycle test and from 1 to $90 \mathrm{MPa}$ for the permeation test, and ambient temperatures ranging from 60 to $100{ }^{\circ} \mathrm{C}$ using a gas compressor and temperature chamber

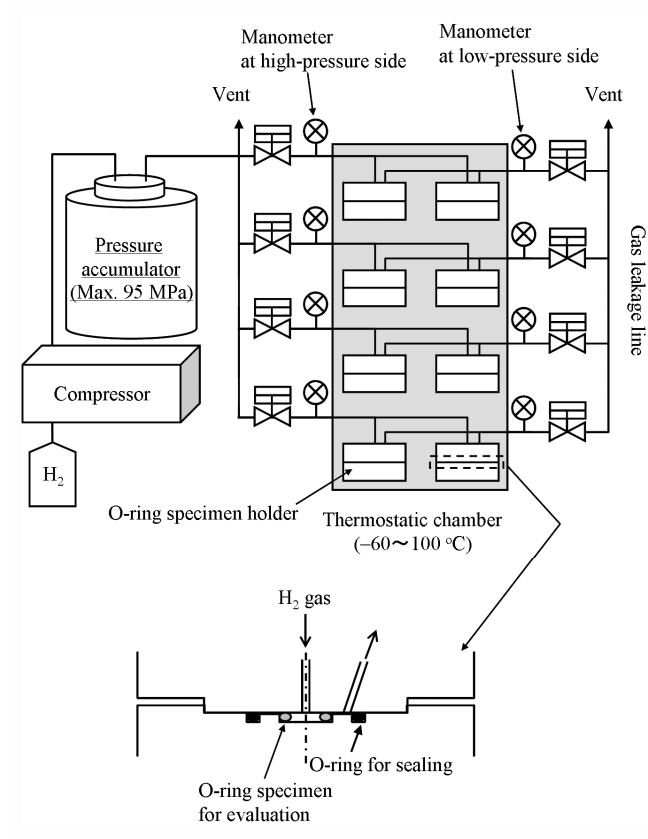

Fig. 1 Schematic representation of high-pressure hydrogen durability tester.

operated by heat media. In this study, pressure cycle tests were conducted at the compression ratio of $16 \%$. In general, the conventional compression ratio ranges from 8 to $30 \%$.

\subsection{Evaluation method of durability of O-ring by orthogonal experiments}

A L18 orthogonal array was employed for evaluating the influence of several factors on the durability of rubber O-rings efficiently. Seven three-level factors and one two-level factor were assigned to this array. Table 2 shows controllable factors, which are low-limit pressure $\left(P_{\mathrm{L}}\right)$, upper-limit pressure $\left(P_{\mathrm{U}}\right)$, material, temperature $(T)$, O-ring filling ratio $(F R)$, holding time at lower limit $\left(t_{\mathrm{L}}\right)$, holding time at upper limit $\left(t_{\mathrm{U}}\right)$ and decompression time $\left(a_{\mathrm{L}}\right)$. The upper-limit pressure is the same meaning as hydrogen pressure $(p)$. Table 3 shows the L18 orthogonal array obtained by using the factors shown in Table 2. The low-limit pressure $\left(P_{\mathrm{L}}\right)$ was assigned to a column with the two-level factor, and the others were assigned to columns with the

Table 1 Material properties

\begin{tabular}{|c|c|c|c|c|}
\hline Items & EPDM & VMQ & HNBR & EPDM (previous study) \\
\hline Properties & Base material & $\begin{array}{c}\text { Low TR10, and high } \\
\text { permeability }\end{array}$ & $\begin{array}{c}\text { High strength, and low } \\
\text { permeability }\end{array}$ & Low hardness \\
\hline \multicolumn{5}{|c|}{ Original properties [JISK6253, JISK6251] } \\
\hline Hardness (Durometer A) & 80 & 80 & 80 & 70 \\
\hline Tensile strength (MPa) & 22.5 & 10.5 & 30.9 & 12.1 \\
\hline Elongation at break $(\%)$ & 200 & 290 & 260 & 330 \\
\hline \multicolumn{5}{|c|}{ Compression set test $\quad$ [JISK6262], $120^{\circ} \mathrm{C} / 70 \mathrm{~h}(\mathrm{EPDM}), 150^{\circ} \mathrm{C} / 70 \mathrm{~h}(\mathrm{VMQ}$ and HNBR) } \\
\hline Compression set $(\%)$ & 6 & 13 & 20 & 18 \\
\hline \multicolumn{5}{|c|}{ Low temperature properties [JISK6261] } \\
\hline TR10 $\left({ }^{\circ} \mathrm{C}\right)$ & -48 & $<-70$ & -22 & -47 \\
\hline \multicolumn{5}{|c|}{ Gas permeability test [JISK7126], Hydrogen gas / $30^{\circ} \mathrm{C} / 0.6 \mathrm{MPa} / 2 \mathrm{~mm}$ Sheet } \\
\hline $\begin{array}{c}\text { Permeability, } Q_{\mathrm{H}} \\
\left(\mathrm{cm}^{3}(\mathrm{STP}) \cdot \mathrm{cm} /\left(\mathrm{cm}^{2} \cdot \mathrm{Pa} \cdot \mathrm{s}\right)\right)\end{array}$ & $3.16 \times 10^{-12}$ & $38.2 \times 10^{-12}$ & $0.95 \times 10^{-12}$ & $3.54 \times 10^{-12}$ \\
\hline \multicolumn{5}{|c|}{ Time-lag method ${ }^{(16)}$, Hydrogen gas $/ 30^{\circ} \mathrm{C} / 0.6 \mathrm{MPa} / 2 \mathrm{~mm}$ Sheet } \\
\hline Diffusivity, $D_{\mathrm{H}}\left(\mathrm{cm}^{2} / \mathrm{s}\right)$ & $3.02 \times 10^{-6}$ & $36.5 \times 10^{-6}$ & $1.38 \times 10^{-6}$ & $8.13 \times 10^{-6}$ \\
\hline $\begin{array}{c}\text { Solubility, } S_{\mathrm{H}} \\
\left(\mathrm{cm}^{3}(\mathrm{STP}) /\left(\mathrm{cm}^{3}(\text { rubber }) \cdot \mathrm{Pa}\right)\right)\end{array}$ & $1.05 \times 10^{-6}$ & $1.05 \times 10^{-6}$ & $0.69 \times 10^{-6}$ & $0.44 \times 10^{-6}$ \\
\hline
\end{tabular}


Table 2 Controllable factors for orthogonal experiments

\begin{tabular}{c|c|c|c|c}
\hline \multicolumn{2}{c|}{ Controllable factors } & Level 1 & Level 2 & Level 3 \\
\hline A & Lower limit pressure: $P_{\mathrm{L}}(\mathrm{MPa})$ & 8 & 1 & - \\
\hline B & Material (Durometer hardness: A80) & EPDM & VMQ & HNBR \\
\hline C & Ambient temperature: $T\left({ }^{\circ} \mathrm{C}\right)$ & 100 & 30 & 0 \\
\hline D & O-ring filling ratio: $F R(\%)$ & 86 & 77 & 67 \\
\hline E & Upper limit pressure: $P_{\mathrm{U}}(\mathrm{MPa})$ & 90 & 35 & 10 \\
\hline F & Holding time at upper limit $: t_{\mathrm{U}}(\mathrm{s})$ & 120 & 60 & 30 \\
\hline G & Holding time at upper limit $: t_{\mathrm{L}}(\mathrm{s})$ & 120 & 60 & 30 \\
\hline $\mathrm{H}$ & Decompression time: $a_{\mathrm{L}}(\mathrm{s})$ & 60 & 10 & 3 \\
\hline
\end{tabular}

Table 3 Test condition of orthogonal experiments

\begin{tabular}{c|c|c|c|c|c|c|c|c}
\hline \multirow{2}{*}{$\begin{array}{c}\text { Test } \\
\text { No. }\end{array}$} & $\mathrm{A}$ & $\mathrm{B}$ & $\mathrm{C}$ & $\mathrm{D}$ & $\mathrm{E}$ & $\mathrm{F}$ & $\mathrm{G}$ & $\mathrm{H}$ \\
\cline { 2 - 9 } & $\begin{array}{c}P_{\mathrm{L}} \\
(\mathrm{MPa})\end{array}$ & Material & $\begin{array}{c}T \\
\left({ }^{\circ} \mathrm{C}\right)\end{array}$ & $\begin{array}{c}F R \\
(\%)\end{array}$ & $\begin{array}{c}P_{\mathrm{U}} \\
(\mathrm{MPa})\end{array}$ & $\begin{array}{c}t_{\mathrm{U}} \\
(\mathrm{s})\end{array}$ & $\begin{array}{c}t_{\mathrm{L}} \\
(\mathrm{s})\end{array}$ & $\begin{array}{c}a_{\mathrm{L}} \\
(\mathrm{s})\end{array}$ \\
\hline 1 & 8 & EPDM & 100 & 86 & 90 & 120 & 120 & 60 \\
\hline 2 & 8 & EPDM & 30 & 77 & 35 & 60 & 60 & 10 \\
\hline 3 & 8 & EPDM & 0 & 67 & 10 & 30 & 30 & 3 \\
\hline 4 & 8 & VMQ & 100 & 86 & 35 & 60 & 30 & 3 \\
\hline 5 & 8 & VMQ & 30 & 77 & 10 & 30 & 120 & 60 \\
\hline 6 & 8 & VMQ & 0 & 67 & 90 & 120 & 60 & 10 \\
\hline 7 & 8 & HNBR & 100 & 77 & 90 & 30 & 60 & 3 \\
\hline 8 & 8 & HNBR & 30 & 67 & 35 & 120 & 30 & 60 \\
\hline 9 & 8 & HNBR & 0 & 86 & 10 & 60 & 120 & 10 \\
\hline 10 & 1 & EPDM & 100 & 67 & 10 & 60 & 60 & 60 \\
\hline 11 & 1 & EPDM & 30 & 86 & 90 & 30 & 30 & 10 \\
\hline 12 & 1 & EPDM & 0 & 77 & 35 & 120 & 120 & 3 \\
\hline 13 & 1 & VMQ & 100 & 77 & 10 & 120 & 30 & 10 \\
\hline 14 & 1 & VMQ & 30 & 67 & 90 & 60 & 120 & 3 \\
\hline 15 & 1 & VMQ & 0 & 86 & 35 & 30 & 60 & 60 \\
\hline 16 & 1 & HNBR & 100 & 67 & 35 & 30 & 120 & 10 \\
\hline 17 & 1 & HNBR & 30 & 86 & 10 & 120 & 60 & 3 \\
\hline 18 & 1 & HNBR & 0 & 77 & 90 & 60 & 30 & 60 \\
\hline & & & & & & \\
\end{tabular}

three-level factors. For each test, the rubber O-rings shown in Table 1 were pressurized at the upper-limit pressure $\left(P_{\mathrm{U}}\right)$ until the amount of gas permeation became steady condition; then, a pressure cycle test was conducted 10 cycles under the condition shown in Table 3. After the test, crack damage of the rubber Orings was evaluated by tensile test mentioned later.

\section{RESULTS AND DISCUSSION}

\subsection{Gas leakage and fracture condition of rubber $O$-ring by pressure cycle test}

Figure 2 (a) shows an example of the amount of gas leakage at the pressure cycle test of No. 1. The material was EPDM, and the test was conducted under the upper-limit pressure of $90 \mathrm{MPa}$ and temperature of $100{ }^{\circ} \mathrm{C}$. In this test, the pressure cycle test was commenced at the elapsed of about 110 minutes. When a constant pressure was applied to the O-ring before the pressure cycle test, the amount of gas leakage $(q)$ was proportional to the elapsed time $(t)$ under steady condition as shown by the dashed line in Figure 2 (a). This $q-t$ relation is generally referred to as a permeation curve; hydrogen gas permeability, diffusivity and solubility can be estimated from this curve ${ }^{(16)}$. In contrast, when a cyclic pressure was applied to the O-ring, the gas leakage increased compared with that of the O-ring subjected to a constant pressure. This tendency was shown in rubber O-rings tested under several conditions.

Figure 2 (b) shows an optical micrograph of the cross section of the rubber O-ring tested under the pressure cycle test of No. 1. Surface and inner cracks were observed from the O-ring as well as the rubber O-rings shown in Fig. 1. From Figs 2 (a) and 2 (b), it is inferred that the increase in the amount of gas leakage at the

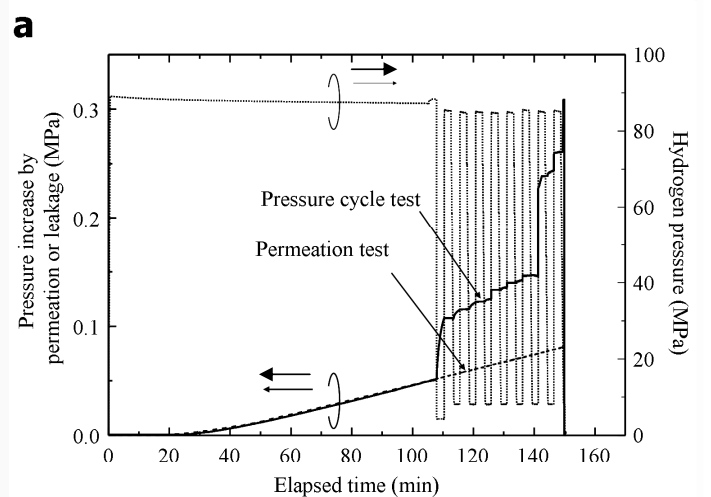

b

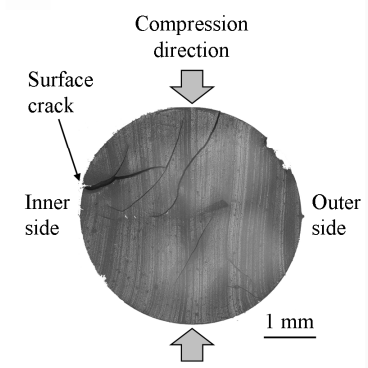

Fig. 2 Gas leakage and crack damage of rubber O-ring used for pressure cycle test of No.1: (a) relationship amount of gas leakage and elapsed time, (b) optical microscope image of cross section of rubber O-ring after pressure cycle test. The test was conducted at a hydrogen pressure at $90 \mathrm{MPa}$ and a temperature of $100{ }^{\circ} \mathrm{C}$.

pressure cycle test is due to the crack damage of the rubber Orings. The surface and inner cracks are considered to be initiated from the following processes:

$\underline{\text { Inner crack }}^{\left({ }^{9}\right.}$

Solute gas molecules become supersaturated due to highpressure hydrogen decompression; then, bubbles are formed and cause the initiation of the inner crack. The inter crack is generally referred to as a blister. In this investigation, the bubble is defined as a cavity filled with hydrogen gas with sizes from submicrometer to micrometer which are hardly observed by optical microscopy, while the crack is defined as a cavity filled with hydrogen gas with sizes more than micrometer which can easily be observed by optical microscopy.

Surface crack ${ }^{(15)}$

Volume increase of the rubber O-ring by swelling extrudes the O-ring from the O-ring holder; then, causes the initiation of the surface crack.

\subsection{Evaluation of mechanical degradation of O-ring}

Since several cracks initiated from the interior of a rubber O-ring at a pressure cycle test, it is difficult to detect these cracks from the appearance inspection of the rubber O-ring. However, it is consider that the fracture force of the rubber O-ring after the pressure cycle test becomes lower than that of a new rubber Oring due to crack initiation. Therefore, we defined the decrease ratio of fracture force of the O-ring due to the crack initiation as follows:

$$
\Delta T_{\mathrm{b}}=\frac{T_{\mathrm{b}}-T_{\mathrm{b} 0}}{T_{\mathrm{b} 0}}
$$


where, $\Delta T_{\mathrm{b}}$ is the decrease ratio of fracture force of the rubber Oring due to the crack initiation; $T_{\mathrm{b} 0}$ is the fracture force of the new O-ring; $T_{\mathrm{b}}$ is the fracture force of the O-ring after the pressure cycle test. The fracture forces of the new O-rings were $392 \mathrm{~N}$ for EPDM, $137 \mathrm{~N}$ for VMQ, and $506 \mathrm{~N}$ for HNBR. The crack damage of the rubber O-rings due to crack initiation was evaluated by using the decrease ratio of fracture force of the $\mathrm{O}$ ring due to the crack initiation $\left(\Delta T_{\mathrm{b}}\right)$ in this study. The tensile test was conducted in air at room temperature under the tensile speed of $500 \mathrm{~mm} / \mathrm{min}$, after solute hydrogen molecules completely diffused out from the rubber O-ring at the pressure cycle test. Two rubber O-rings were tested by each test condition $\left(\Delta T_{\mathrm{b} 1}, \Delta T_{\mathrm{b} 2}\right)$, and the smaller-the-better signal-to-noise $(\mathrm{S} / \mathrm{N})$ ratio $(\eta)$ was calculated as follows:

$$
\eta=-10 \log \left\{\frac{1}{2}\left(\Delta T_{\mathrm{b} 1}^{2}+\Delta T_{\mathrm{b} 2}^{2}\right)\right\}
$$

When the smaller-the-better $\mathrm{S} / \mathrm{N}$ ratio $(\eta)$ becomes larger, the decrease ratio of fracture force of the O-ring due to the crack initiation $\left(\Delta T_{\mathrm{b}}\right)$ becomes smaller, i.e., crack damage of the O-ring becomes slighter. Table 4 shows the smaller-the-better $\mathrm{S} / \mathrm{N}$ ratios $(\eta)$ of the rubber O-rings. The $\eta$ value of the O-ring used for No. 5 was the highest, while that of the O-ring used for No. 1 was the lowest.

Figure 3 shows optical micrographs of the cross sections of the rubber O-rings with the maximum and minimum $\eta$ values, and approximately average $\eta$ value. The materials employed for the tests of No.1, No. 5, and No. 18 were EPDM, VMQ, and HNBR, respectively. Several cracks with millimeter-size were observed from the O-ring used for the test of No.1, whereas no cracks were observed from the O-ring used for No. 5. Furthermore, cracks with micrometer-size were observed from the O-ring used for No. 18. From the crack damage and the smallerthe-better S / $\mathrm{N}$ ratio, the crack damage of the rubber O-rings became slighter with an increase in the $\eta$ value. Therefore, it was judged that relative evaluation of crack damage could be conducted in terms of the smaller-the-better $\mathrm{S} / \mathrm{N}$ ratio.

Table 4 Decrease ratio of tensile force due to crack initiation and smaller-the-better $\mathrm{S} / \mathrm{N}$ ratio

\begin{tabular}{c|c|c|c}
\hline \multirow{2}{*}{ Test No. } & \multicolumn{2}{|c}{$\Delta T_{\mathrm{b}}$} & \multirow{2}{*}{$\begin{array}{c}\text { Smaller-the-better } \\
\text { S/N ratio (dB) }\end{array}$} \\
\cline { 2 - 3 } & $n=1$ & $n=2$ & 3.7 \\
\hline 1 & -0.615 & -0.688 & 17.9 \\
\hline 2 & -0.150 & -0.100 & 12.3 \\
\hline 3 & -0.238 & -0.250 & 7.1 \\
\hline 4 & -0.436 & -0.443 & 45.9 \\
\hline 5 & 0.000 & -0.007 & 22.3 \\
\hline 6 & -0.043 & -0.100 & 6.2 \\
\hline 7 & -0.477 & -0.502 & 16.1 \\
\hline 8 & -0.174 & -0.138 & 19.7 \\
\hline 9 & -0.116 & -0.089 & 18.1 \\
\hline 10 & -0.075 & -0.160 & 13.4 \\
\hline 11 & -0.160 & -0.255 & 14.1 \\
\hline 12 & -0.140 & -0.243 & 27.4 \\
\hline 13 & -0.043 & -0.043 & 19.0 \\
\hline 14 & -0.093 & -0.129 & 27.3 \\
\hline 15 & -0.021 & -0.057 & 18.3 \\
\hline 16 & -0.045 & -0.167 & 32.2 \\
\hline 17 & -0.147 & -0.128 &
\end{tabular}
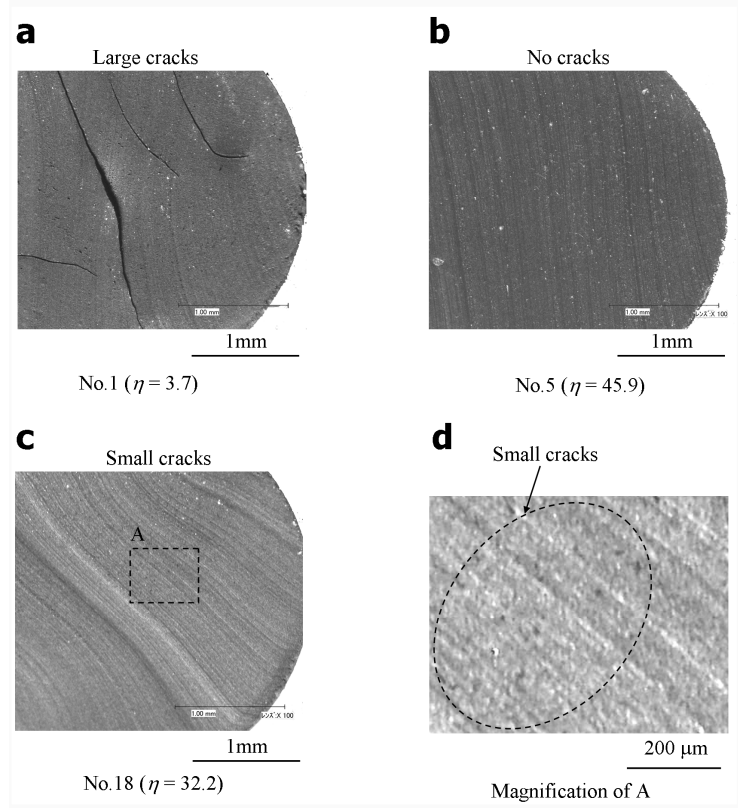

Fig. 3 Optical micrographs of the cross sections of the rubber O-rings: (a) EPDM (Test No. 1), (b) VMQ (Test No. 5), (c) HNBR (Test No. 18), (d) magnification of A.

\subsection{Evaluation of influencing factors by analysis of variance (ANOVA) table and graph of fractional effects}

In order to clarify influencing factors on the crack damage of rubber O-rings, variance analysis was conducted ${ }^{(10-12)}$. Table 5 shows ANOVA table. The mean squares $(M S)$ of the holding time at upper limit and holding time at lower limit were 21.5 and 7.9, respectively. Since these values were smaller than that of error $(M S=31.1)$, these factors were pooled. By pooling the holding time at upper limit and holding time at lower limit, the analysis of variance table on the L18 factors was conducted again. The variance ratio $\left(F_{0}\right)$, which is the ratio of factor to error in terms of the mean squares expressed by equation 3 , is also shown in Table 5 .

$$
F_{0}=\frac{M S(\text { Factor })}{M S(\text { Error })}
$$

where, $M S$ (Factor) is the mean squares of the factors; $M S$ (Error) is the mean squares of the error. Whether factors influence crack damage or not is evaluated from $F$ tests. When the degree of freedom of the factor is $\phi_{\mathrm{F}}$ and that of the error is $\phi_{\mathrm{E}}$, the condition that the factors influence crack damage can be expressed under significance level $(\alpha)$ as follows:

$$
F_{0} \geq F\left(\phi_{\mathrm{F}}, \phi_{\mathrm{E}} ; \alpha\right)
$$

The significance level is generally set to be 0.05 , and the $F$ distribution table indicates that $F(1,6 ; 0.05)=5.99$ and $F(2,6$; $0.05)=5.14$. From Table 5 , the factors influencing on the crack damage ranked the material, decompression time, O-ring filling ratio, and temperature in descending order. Although the hydrogen pressure (upper-limit pressure) was not an influencing factor in terms of ANOVA, it is inferred that this factor also influences crack damage, since its crack damage became more serious with an increase in hydrogen pressure ${ }^{(15)}$.

Figure 4 shows the graph of fractional effects on crack damage of the rubber O-rings. As for the material, the $\eta$ value of VMQ 
Table 5 Analysis of variance (ANOVA) table

\begin{tabular}{|c|c|c|c|c|c|c|c|c|c|}
\hline $\begin{array}{l}\text { Controllable } \\
\text { Factors }^{* 1}\end{array}$ & $f$ & $S$ & $M S$ & & $f$ & $S$ & $M S$ & $F_{0}(\%)$ & $R^{2}$ \\
\hline Lower limit pressure & 1 & 71.2 & 71.2 & & 1 & 71.2 & 71.2 & 3.53 & 0.03 \\
\hline Material & 2 & 404.8 & 202.4 & & 2 & 404.8 & 202.4 & $10.04^{* 2}$ & 0.21 \\
\hline Temperature & 2 & 255.1 & 127.6 & & 2 & 255.1 & 127.6 & $6.32^{* 2}$ & 0.13 \\
\hline O-ring filling ratio & 2 & 265.8 & 132.9 & & 2 & 265.8 & 132.9 & $6.59^{* 2}$ & 0.13 \\
\hline Upper limit pressure & 2 & 195.5 & 97.7 & $\Rightarrow$ & 2 & 195.5 & 97.7 & 4.85 & 0.09 \\
\hline $\begin{array}{c}\text { Holding time at } \\
\text { upper limit }\end{array}$ & 2 & 43.0 & 21.5 & & \multicolumn{5}{|c|}{ Pooling } \\
\hline $\begin{array}{c}\text { Holding time at } \\
\text { lower limit }\end{array}$ & 2 & 15.9 & 7.9 & & \multicolumn{5}{|c|}{ Pooling } \\
\hline Decompression time & 2 & 388.4 & 194.2 & & 2 & 388.4 & 194.2 & $9.63^{* 2}$ & 0.21 \\
\hline Error & 2 & 62.1 & 31.1 & & 6 & 121 & 20.2 & 3.53 & 0.20 \\
\hline Total & 17 & 1701.8 & & & 17 & 1701.8 & & 100.0 & 1.00 \\
\hline
\end{tabular}

was the largest; therefore, VMQ showed the slightest crack damage. As for the temperature, the $\eta$ value at $100{ }^{\circ} \mathrm{C}$ was the lowest; therefore, the crack damage became more serious with an increase in the temperature. As for the O-ring filling ratio, the $\eta$ value when the O-ring filling ratio was $77 \%$ was the largest. The result implies that the optimum value of the O-ring filling ratio exists for crack damage. As for the decompression time, the $\eta$ value became larger, i.e., the crack damage became more serious when the decompression time became longer. We investigated how these factors influenced the crack damage of the O-rings. Material

When a hydrogen-exposed rubber O-ring is decompressed, solute hydrogen molecules becomes supersaturated; then, bubbles are formed in the interior of the O-ring and cause crack initiation. Yamabe et. al estimated the critical hydrogen pressures at crack initiation $\left(\Pi_{\mathrm{F}}\right)$ of several rubber materials in terms of fracture mechanics criterion ${ }^{(7)}$ and maximum principal criterion ${ }^{(6)}$; then, the maximum principal criterion indicated that the $\Pi_{F}$ value became higher when mechanical properties such as tensile elastic modulus and tensile strength were improved. Furthermore, it was indicated that the crack damage of the rubber O-ring became

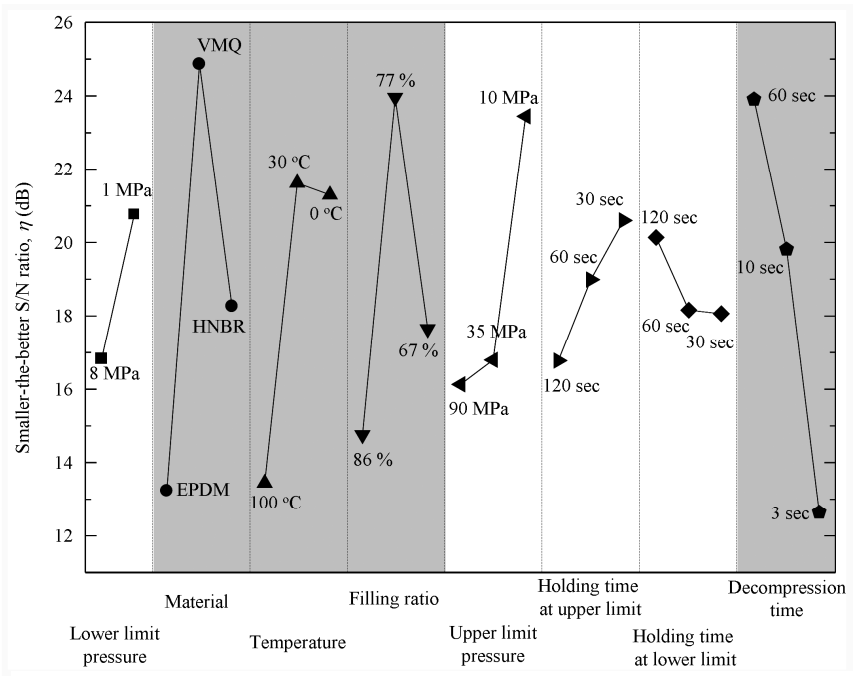

Fig. 4 Graph of fractional effects on crack damage of rubber O-rings slighter with an increase in the $\Pi_{\mathrm{F}}$ value; then, the $\Pi_{\mathrm{F}}$ value could be regarded as a resistance to crack initiation. The tensile elastic modulus is related to hardness. Since the hardness of EPDM, VMQ, and HNBR is the same as known from Table 1, it is considered that the $\Pi_{F}$ value depends on the tensile strength.

In contrast, the internal pressure acting on a bubble (П) depends on solute hydrogen concentration at the sites around the bubble $\left(c_{\mathrm{H}}\right)$. After high-pressure hydrogen decompression, the hydrogen molecules dissolved in the rubber structure with a high diffusivity diffuse out faster than those dissolved in the rubber with a low diffusivity under the condition that the shape and dimensions of specimen are the same. In other words, hydrogen molecules dissolved in the rubber with a low diffusivity retain in the rubber matrix for a longer time than those dissolved in the rubber with a high diffusivity. In this case, the bubble formed in the rubber with a low diffusivity is subjected to a high internal pressure for a longer time than that formed in the rubber with a high diffusivity. As a result, the crack damage of the rubber with a low diffusivity is believed to be more serious than that of the rubber with a high diffusivity under the same $\Pi_{F}$ value.

From this viewpoint, it is believed that the crack damage of the rubber O-rings used in this study is influenced by tensile strength, which is a resistance to crack initiation, and hydrogen gas diffusivity, which is a driving force for crack initiation. Hydrogen gas solubility also becomes a driving force for crack initiation $^{(6)}$; however, as the first approximation, the smaller-thebetter $\mathrm{S} / \mathrm{N}$ ratio $(\eta)$ was conventionally estimated by using hydrogen gas diffusivity at $30{ }^{\circ} \mathrm{C}\left(D_{\mathrm{H}}\right)$ and tensile strength in air at room temperature $\left(\sigma_{\mathrm{B}}\right)$ as follows:

$$
\eta=a D_{\mathrm{H}}+b \sigma_{\mathrm{B}}
$$

where, $a$ and $b$ are experimental constants, which were estimated by using the least square method. As a result, the following result was obtained:

$$
\eta=\left(5.267 \times 10^{5}\right) D_{\mathrm{H}}+0.546 \sigma_{\mathrm{B}} \quad\left(R^{2}=0.99\right)
$$

where, $R^{2}$ is the determination coefficient. Although explanatory variables were not many, we got a high determination coefficient. When the $\eta$ value of EPDM-L was estimated, we obtained that $\eta$ 
$=10.9$. This result implies that the crack damage of EPDM-L is more serious than that of the other rubbers (EPDM, VMQ and HNBR). Observations of cross sections of the rubber O-rings by optical microscopy indicated that the crack damage of EPDM-L was more serious than that of the others, although the experimental $\eta$ value was not obtained. Based on equation 6 , VMQ had a one-order higher diffusivity than the others (EPDM, HNBR) in spite of the lowest tensile strength; therefore, the crack damage of VMQ was believed to be the slightest, i.e., the $\eta$ value was the largest. Since the hydrogen gas diffusivity of HNBR was comparable with that of EPDM, these crack damages were influenced by the tensile strength; therefore, the crack damage of HNBR was believed to be slighter than that of the EPDM.

Decompression time

When decompression time (rate) becomes shorter (faster), the hydrogen molecules dissolved in a rubber O-ring become more supersaturated; therefore, it is inferred that the crack damage of the O-rings generally becomes more serious when decompression time becomes shorter. The crack damage of the rubber O-rings used in this study was also influenced by decompression time (rate) as well as the results of several previous studies ${ }^{(1-3)}$. O-ring filling ratio

The crack damage of the rubber O-ring was the slightest when the O-ring filling ratio was $77 \%$ as known from Figure 4. This result implies that the optimum O-ring filling ratio exists for crack damage. Figure 5 shows examples of crack damage of rubber O-rings, whose material is EPDM-L. The rubber O-rings were set to the O-ring holder with a difference O-ring filling ratio. These O-rings were exposed to high-pressure hydrogen gas at 35 $\mathrm{MPa}$ and $100{ }^{\circ} \mathrm{C}$ for 15 hours; then, were once decompressed. When O-ring filling ratio is high, it is believed that the rubber Oring is extruded from the O-ring holder due to volume increase by swelling; then, a surface crack is initiated as shown in Fig. 5 (a). In contrast, when O-ring filling ratio is low, it is believed that the O-ring bends due to volume increase by swelling; then, a surface crack is initiated as shown in Fig. 5 (b). Since fracture modes differ by the O-ring filling ratio as shown in Fig. 5, it is inferred that the optimum O-ring filling ratio existed for the crack damage

a

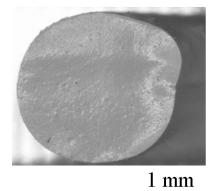

(a-1-1) Cross section (Plastic deformation)

(a-1) Optical micrographs

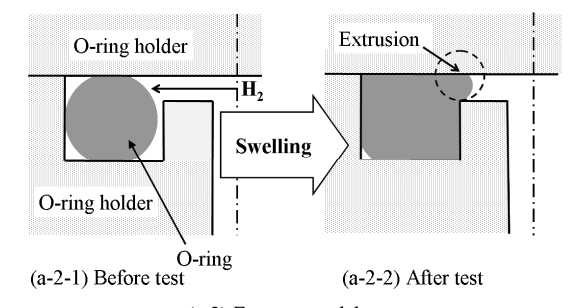

(a-2) Fracture model of rubber O-rings.

\section{Temperature}

Figure 6 shows the influence of temperature on tensile strength of EPDM, VMQ, and HNBR. A type-3 dumbbell specimen ${ }^{(17)}$ with a thickness of $2 \mathrm{~mm}$ was elongated at a crosshead speed of $500 \mathrm{~mm} / \mathrm{min}$ in air. The tensile strength of EPDM, VMQ, and HNBR decreased with an increase in temperature. The resistance to crack initiation decreases with a decrease in the tensile strength ${ }^{(6)}$. Due to this, it is believed that the crack damage of EPDM, VMQ, and HNBR became more serious with an increase in the temperature.

Finally, the factors influencing on the crack damage of rubber O-rings were the material, decompression time (rate), Oring filling ratio, and temperature from the analysis of variance table as mentioned. Furthermore, it was implied that the hydrogen pressure influenced crack damage from our previous studies ${ }^{(14,15)}$. Of these factors, the material is the most sensible factor; gives a strong influence on the durability of rubber O-rings. For the seals in high-pressure hydrogen service, gas barrier property is demanded as well as the durability. The gas barrier property corresponds to hydrogen gas permeability $\left(Q_{\mathrm{H}}\right)$; the rubber O-ring with a low permeability has excellent gas barrier property. Although VMQ has an excellent durability, this has a poor gas

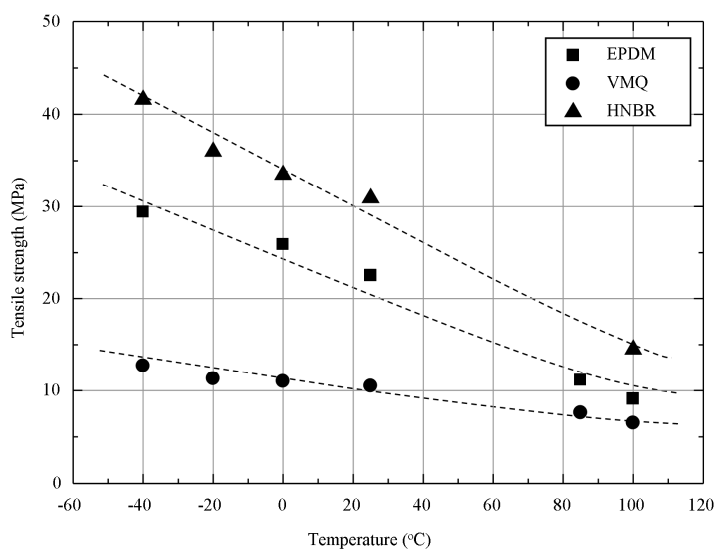

Fig. 6 Influence of temperature on tensile strength of rubbers.

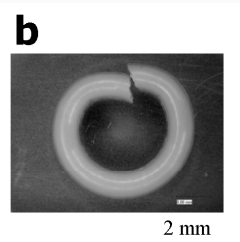

(b-1-1) Appearance

(Example 1)

(b-1) Optical micrographs

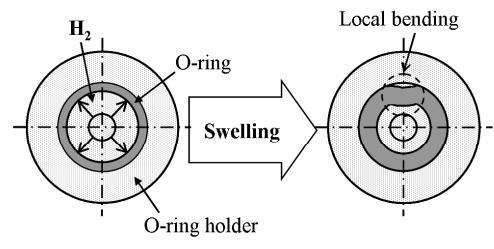

(b-2-1) Before test

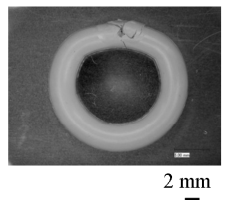

(b-1-2) Appearance (Example 2)

$(\mathrm{b}-2-2$ (b-2) Fracture mode

Fig. 5 Influence of O-ring filling ration on fracture behavior of rubber O-ring: (a) fracture at high filling ratio, (b) fracture at low filling ratio. EPDM with a hardness of A70 was exposed to hydrogen gas at $35 \mathrm{MPa}$ and $100^{\circ} \mathrm{C}$ for 15 hours; then, was decompressed. 
barrier property. Therefore, a balanced material in terms of the durability and gas barrier property is needed for the seals in highpressure hydrogen environment. Furthermore, the decompression time (rate) also gives a strong influence on the durability. When decompression rate becomes slower, the durability of rubber Orings is considerably improved. Therefore, it will be needed to develop the system which can control decompression rate in terms of durability. Furthermore, since a remarkable volume increase of rubber O-rings by swelling occurs at pressures in excess of 35 $\mathrm{MPa}$; causes crack initiation, the design of a sealing holder in high-pressure hydrogen environment will also be indispensable.

\section{CONCLUSION}

In order to clarify the influences of several factors such material and decompression time on crack damage of rubber Orings under high-pressure hydrogen environment, a L18 orthogonal array was employed, and influencing factors on crack damage of rubber O-rings were investigated. Eight factors, which lower-limit pressure, upper-limit pressure, material, temperature, O-ring filling ratio, holding time at lower limit, holding time at upper limit, and decompression time, were selected for controllable factors. The durability test was conducted by a highpressure hydrogen durability tester which enables rubber O-rings to repeatedly expose high-pressure hydrogen gas. The results obtained can be summarized as follows:

1. From the graph of fractional effects and analysis of variance table, it was clarified that the material, temperature, O-ring filling ratio, and decompression time were sensitive factors.

2. The amount of gas leakage of a rubber O-ring under a cyclic pressure was higher than that under a constant pressure. Since several surface and inner cracks were observed from the rubber O-ring after the pressure cycle test, it was inferred that the increase in the amount of gas leakage was due to crack initiation. 3. The mechanical damage of the rubber O-ring due to surface and inner cracks was evaluated by using the decrease ratio of fracture force of the O-ring due to the crack initiation $\left(\Delta T_{\mathrm{b}}\right)$. The crack damage of VMQ was the slightest in spite of the lowest tensile strength. Since VMQ has a one-order higher diffusivity than the others (EPDM, HNBR), solute hydrogen molecules diffuse out faster than those in the others after decompression. Due to this, it is inferred that the crack damage of VMQ was the slightest.

4. The crack damage became more serious with a decrease in decompression time as well as the results reported in several previous studies.

5. When O-ring filling ratio was high, the rubber O-ring was extruded from the O-ring holder due to volume increase by swelling; then, a surface crack was initiated. In contrast, when Oring filling ratio was low, the O-ring bended due to volume increase by swelling; then, a surface crack was initiated. Since fracture modes differ by the O-ring filling ratio, it is inferred that the optimum O-ring filling ratio existed for the crack damage of rubber O-rings.

6. The tensile strength of the rubber O-rings decreased with an increase in temperature. Since the resistance to crack initiation decreases with a decrease in the tensile strength, it is believed that the crack damage of the rubber O-rings became more serious with an increase in the temperature.

\section{Acknowledgement}

This research has been supported by the NEDO project "Fundamental Research Project on Advanced Hydrogen Science (2006-2012).”

\section{References}

(1) BJ. Briscoe, T. Savvas, CT. Kelly: Explosive decompression failure of rubber: Rubber Chem. Technol., 67(1994), pp. 384-416.

(2) S. Zakaria, BJ. Bricoe: Why rubber explodes: Chemtech, 20(1990), pp. 492-495.

(3) DH. Ender: Elastomeric seals: Chemtech, 16(1986), pp. 52-57.

(4) AN. Gent, DA. Tompkins: Nucleation and growth of gas bubbles in elastomers: J. Appl. Phys., 40(1969), pp. 2520-2525.

(5) A. Stevenson, M. Glyn: Fracture of elastomers by gas decompression. Rubber Chem. Technol., 68(1995), pp. 197-211.

(6) J. Yamabe, S. Nishimura: Influence of fillers on hydrogen penetration properties and blister fracture of rubber composites for O-ring exposed to high-pressure hydrogen gas: Int. J. Hydrogen Energy, 34(2009), pp. 1977-1989.

(7) J. Yamabe, S. Nishimura: Estimation of Critical Pressure of Decompression Failure of EPDM Composites for Sealing under High Pressured Hydrogen Gas: Proc. of the 18th European Conference on Fracture (2010), CD-DOM.

(8) J. Yamabe, T. Matsumoto, S. Nishimura: Application of acoustic emission method to detection of internal fracture of sealing rubber material by high-pressure hydrogen decompression: Polym. Test., 30(2011), pp. 75-85.

(9) J. Yamabe, S. Nishimura: Nanoscale Fracture Analysis by Atomic Force Microscopy of EPDM rubber due to High-Pressure Hydrogen Decompression: J. Mat. Sci., 67(2011), pp. 2300-2307.

(10) K. Hinkelmann, O. Kempthorne: Design and Analysis of Experiments, Vol. 2, Advanced Experimental Design: WileyInterscience (2005).

(11) H. Toutenburg: Statistical Analysis of Designed Experiments. 2nd ed: Springer (2001).

(12) M. Miyagawa: Technology for Getting Quality, What the Taguchi Method Has Brought Us: JUSE Press. Ltd (2003).

(13) PJ. Ross: Taguchi Techniques for Quality Engineering: McGraw-Hill (1988).

(14) J. Yamabe, S. Nishimura, A. Koga: A Study on Sealing Behavior of Rubber O-ring in High Pressure Hydrogen Gas: SAE Int. J. Mater. Manuf., 2(2009), pp. $452-460$

(15) J. Yamabe, A. Koga, S. Nishimura: Durability and Hydrogen Permeation Properties of Sealing Rubber under High Pressure Hydrogen Gas: Nippon Gomu Kyokaishi, 83(2010), pp. 159-166

(16) GJ. Van Amerongen: Diffusion in elastomers: Rubber Chem. Technol., 37(1964), pp. 1067-1152.

(17) JIS K 6251: Rubber, vulcanized or thermoplasticDetermination of tensile stress-strain properties: Japanese Industrial Standards (2004). 